\title{
SHARED UNDERSTANDING: THE MACHINE CODE OF THE SOCIAL IN A SOCIO-TECHNICAL SYSTEM
}

\author{
Christine Pasquire ${ }^{1}$ and Paul Ebbs ${ }^{2}$
}

\begin{abstract}
The emergence of the explicit need for shared understanding as an underpinning flow in lean construction has generated some debate and exposed a need to provide a better explanation. Following an investigation comprising of a total of 27 interviews and several workshops, the data identifies and connects the relationship between inappropriate understanding and constraints to flow represented through a conceptual model. The research further identified that introducing lean construction concepts associated with the Last Planner® System caused the participants to realise the importance of a shared understanding when previously they had not raised it as a source of constraint or problem. The research concludes that a shared understanding is critical to the social aspects of a sociotechnical system and needs to be precise and project specific to achieve the desired outcomes. In this way, a shared understanding can be considered to be the equivalent of a machine code in an operating system - if the understanding breaks down then so does the project delivery system.
\end{abstract}

Keywords: 8th flow; common understanding; shared understanding; lean construction

\section{INTRODUCTION}

It was proposed by Pasquire (2013) based on a reivew of lean construction practice and theory, that a common understanding formed the eighth flow of lean construction, adding to the seven flows identified in construction physics (Bertelsen et al. 2007). Flow has long been established as a lean principle with Just in Time forming one of the pillars of the Toyota Production System (TPS) (Liker 2004). Similarly, the importance of creating a common understanding is apparent within many aspects of TPS (Pasquire 2013). Furthermore, the occurrence of actions to generate understanding is observed within the implementation of a lean construction system when examined retrospectively (Pasquire \& Court 2014). However, although Pasquire \& Court (2014) identify that knowledge is an important part of a common understanding, more work is needed to create a better explanation of the phenomenon and provide evidence of its existence and form. In his theoretical discussion on the eighth flow, Andersen (2016) relates understanding and Communities of Knowledge ( $\mathrm{CoK}$ ) to the semantic dimension of language, which he claims fails to determine the outer reality. He proposes that a unified, outer experience or model to enable "real external production" is needed and he continues to describe the form this might take. This description includes proposals regarding the alignment of human action through a material order approach within an organisational system in an attempt to widen the lean construction debate (Andersen 2016). The integration of human action and the

Professor of Lean Project Management; Centre for Lean Projects, School of Architecture, Design and Built Environment, Nottingham Trent University, UK. christine.pasquire@ntu.ac.uk

2 Research Fellow; Centre for Lean Projects, School of Architecture, Design and Built Environment, Nottingham Trent University, UK paul.ebbs@ntu.ac.uk 
systematic material order approach can be described as socio-technical and aligns with the idea of lean construction as socio-technical system. Seymour (1996) introduced sociotechnical systems to the IGLC body of knowledge and recognised the importance of describing how human actors bring themselves to bear upon the technical production: "... look more carefully at the theories that are actually there, in use; to find out how they are used in particular settings and for what particular purposes. That is, not to construct theories about people but to find out the theories of people (their theories) and to establish how they are used."(Seymour 1996 p3.)

Seymour's (1996) early contribution has resonated within much of the later practical and theoretical development of lean construction. His particular reference to the "ghost in the machine" (Ryle 1963 cited in Seymour 1996 p.2) is a good description of how people may appear within systems - ethereal and potentially disruptive to organisational, economic and technical engineering being directed without bottom up consideration. Clearly, the social aspect of socio-technical systems are important and the language used in conversations is critical to sharing knowledge and communicating ideas, and to how these ideas are understood and more importantly acted upon. The language becomes the means of operation for the project in much the same way that a machine code exists to turn switches on or off and facilitate interoperatibility through standardisation. A principal difference however is that machine code mostly operates through a binary on/off language whereas human language stimulates many billions of chemical reactions in the brain albeit still finally in a binary on/off mechnism. The combination of these reactions affect mood, memory and action in a very pesonal way making a homogeonized reaction across a number of individuals not only impossible but also undesirable not least for the reasons stated by Abderson (2016). The difficulty is encountered as the future of a project is invented through the language used in conversations specifically by:

- what is or what is not said

- what is or what is not heard

- what is or what is not understood, and

- what action is or what action is not taken

In the simplest terms, action is what gets work done; knowledge and ideas are what drive the design of the work to be done (from project inception to last planner). To illustrate the importance of understanding taking into consideration Seymour's suggestion that the people are consulted, research is being undertaken within an organisation seeking to transform itself into lean project delivery enterprise. Referred to as Organisation X in this paper. Part of this research has tested aspects of the relationship between all eight flows of lean construction and constraint management as part of make ready under the Last Planner ${ }^{\circledR}$ System (LPS). It is reported by Daniel (2017) that a number of path clearing activities are required at organisational level prior to implementing LPS and these informed the research. Organisation $\mathrm{X}$ has 150 employees and provides project management services to a UK Government Agency in a highly regulated engineering sector. The projects are generally closer to simple and straightforward than complex and difficult, but the stringency of the operating regulations adds a significant layer of complication particularly at the front end. They have several departments in addition to project management. These include Safety, Health, Environment and Quality (SHEQ); Procurement; Legal; and Human Resources (HR). These departments operate in traditional silos separated physically and operationally within a hierarchical organisational structure. The only inter-departmental team is the Management Lead Team of departmental heads, who meet weekly with Directors to review performance. 


\section{RESEARCH METHOD}

The research reported here is part of an action research project funded directly by Organisation X for a duration of 24 months. The principal purpose of the action research is the development of a bespoke lean project delivery system that makes project delivery more reliable. An early part of the project required the investigation of the current operational process of the organisation and constraints to this. There were four steps in the research process with each step supporting subsequent steps: Step 1 - Exploratory interviews; Step 2 - a set of workshops; Step 3 - Interviews specific to planning \& control practices and procedures; Step 4 - Development of a conceptual model illustrating the importance of understanding to flow in project delivery.

Step 1 - the first research activity was a series of 14 exploratory interviews. The interview sample included members of each department (excluding HR) at various management levels. The interviews were conducted in private with assured confidentiality and anonymity in order to increase the degree of honesty in the responses. A semistructured survey instrument was used to enable the exploration of issues within a common framework of topics. The interviews were audio recorded, transcribed and analysed using Thematic Analysis.

Step 2 - two mini preparatory workshops were held in advance of a one-day workshop. The purpose was to flush out the initial constraint categories in each of the 8 Flows: prior work; materials; information; equipment; people; space; external conditions; understanding. Subsequently, a one-day workshop where a refreshed sample of 15 staff members participated (including 8 people that were not included in the interview sample). The workshop began by creating a "current state" flow chart of Organisation X (non-lean) project delivery process followed by an introduction to the theory of flow in lean project delivery. This was followed by a number of breakout sessions facilitated by the research team in which each group considered how each of the 8 Flows identified by Pasquire (2013) were constrained during the delivery of projects by answering the question "What are the constraints (relating to the named flow) that disrupt project delivery here? i.e. what stops you from working?". This resulted in 12 new constraints being added and four being removed from those identified in Steps 1 \& 2. A total of 142 constraints were assigned across the eight flows. These 142 constraints were then prioritised $(n=22)$ and the level of impact assessed by a simple voting system ( $n=266$ total votes cast).

Step 3 - additional semi-structured interviews $(n=13)$ took place. This included staff from business/project planning $(n=4)$; project engineers $(n=2)$; procurement including QS $(n=3)$; project managers $(n=2)$; SHEQ $(n=2)$. Current and future planning \& control practices and procedures were investigated under themes such as: what's working well/what's not working (traditionally \& LPS); people's role in planning; how plans \& project status get communicated; how commitments are made \& the consequence of missed commitments; control mechanisms used; the accuracy of plans vs actual work underway; LPS metrics; constraints to personal work; and planning \& control improvement suggestions.

Step 4 - the combination of interviews and workshops provided a significant body of rich, qualitative, primary data with many uses. For the purposes of the research reported here, this data was analysed using a lens of "Understanding" to try to provide a conceptual model of how understanding impacts upon the eight flows of a project process (Figure 2). 


\section{RESULTS}

\subsection{Data analysis}

Table 1 illustrates a sample of the 22 constraints identified through Step 2 including their perceived Level Of Impact (LOI), the number of votes assigned and which flows were affected.

Table 1: Sample of constraints $(n=22)$ identified from the flow walks

\begin{tabular}{|l|l|l|l|}
\hline LOI & Constraint & Votes & Affected Flows \\
\hline $1 \mathrm{a}$ & Scope & 33 & Information, Ext. Conditions, Materials \\
\hline $1 \mathrm{~b}$ & Sign-off Process & 33 & Information, Material, Prior Activity \\
\hline 2 & Resource/Priority Planning & 24 & Understanding, Ext. Conditions, Space \\
\hline 3 & Commitments & 23 & Understanding, Ext. Conditions \\
\hline 13 & Office Environment & 6 & People, Space \\
\hline 14 & Centralised Decisions & 5 & People \\
\hline 15 & Lack of Standard Work & 4 & Understanding \\
\cline { 2 - 4 } & Bottleneck of Key Resources & 4 & People \\
\hline \multirow{2}{*}{16} & Overuse of Modification Doc & 3 & Understanding \\
\cline { 2 - 4 } & Security Clearance & 3 & Prior Activity \\
\hline \multirow{2}{*}{17} & Unknown Risks & 2 & Understanding \\
\hline
\end{tabular}

Each of the steps within the current state project delivery process of Organisation X were screened against each of the 22 constraints to identify specific areas of future focus. The constraints "Resource/Priority Planning" (LOI \#2) and "Commitments" (LOI \#3) were identified as the constraints with the biggest LOI on Organisation X's "current state" project delivery - impacting over $50 \%$ of the 31 stages identified in the current process..

Of the total number of 22 constraints identified by the participants during Step 2, only 10 constraints $(45 \%)$ were linked to the $8^{\text {th }}$ Flow: Shared Understanding. However, the more the data is interrogated, the clearer the impact of "Understanding" becomes on each constraint. For example, if we unpack LOI \#1a Scope, $25 \%$ of its votes were attached to "Ambiguous/Unclear Scope" and "Assumptions in Work Package". One suspects that if anything is deemed "ambiguous" or is "assumed" a shared understanding is unlikely. Similarly, if we look at LOI \#1b "Sign-off Process", the are three references to "unnecessary purchase requisitions". If unnecessary work is being carried out, a shared understanding of "next" customer requirements cannot exist because the work would not proceed if it was unnecessary.

The breakdown shown in Figure 1 is the distribution of over 1000 statements across 21 themes identified. Additional sub-codes were created within these themes. The interview content describes the way the particpants view their operational processes relative to the sub-set of questions outlined in Step 3 of the methodology. These processes largely revolve around the preparation of project documentation to facilitate designing (engineering), procuring and constructing a variety of projects. The interview transcripts were themed and coded deductively and then analysed through a lens of understanding.

Figure 1: Thematic analysis results from Step 3 


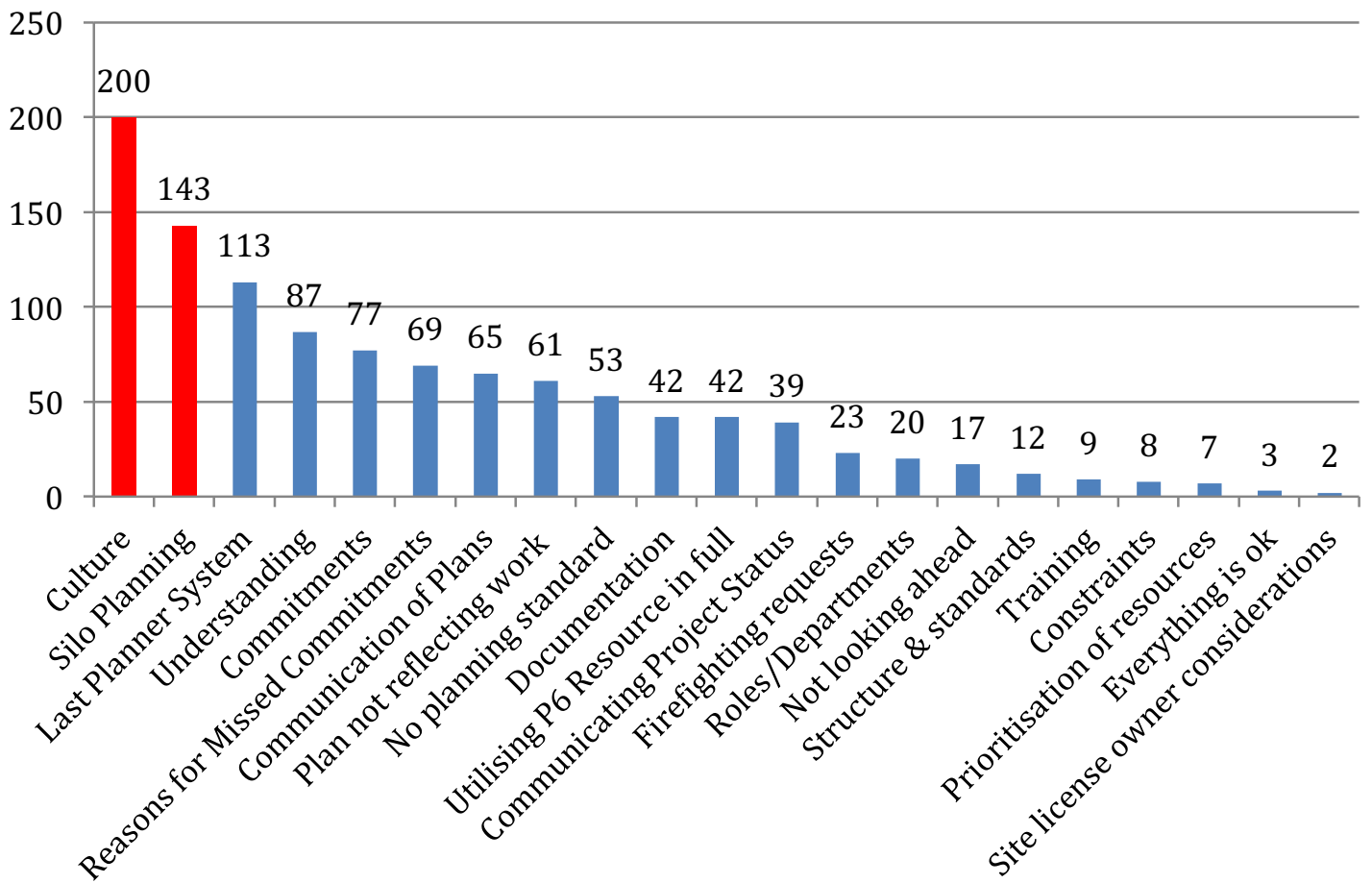

The qualitative nature of the data gave some subjectivity to the analysis and many statements fell into more than one coded theme. This allowed a number of differing analyses to be undertaken, however these analyses showed that even though the instances in each code varied the principal issues remained constant. For example, the culture theme had more sub codes related to a culture of: 1) team work - us (33 instances); 2) silo work - them (115); 3) no consequence (14); 4) negativity (9); 5) organisational inertia (14). The high proportion of references towards "them" within this theme helps to explain the other issues identified within the other themes shown in Figure 1 such as: silo planning; communication of plans; plans not reflecting actual work; communication of project status; documentation (production \& review); commitments; alignment of priorities; roles/department functions; and reasons for missed commitments (RMC) - which included learning (15), no investigation (14) or trending (18) of the reasons why commitments are missed. If we also unpack the theme of shared understanding, implicit or explicit reference was made to issues relating to understanding in five key areas: 1) people (38 instances); 2 ) documentation (14); 3) plans (14); 4) project purpose (12); and learning (8).

From the data within Figure 1 combined with the previous research steps (1 through 4) it can be seen that when understanding is explicitly considered as a flow, the constraints that arise are mostly associated with lean project delivery, which suggests understanding is something integral to lean. Examination of the data identifies four problems associated with understanding.

Firstly, constraints are the result of isolated or personal (silo) understanding (i.e. not shared) - for example individual interpretation; impact of stakeholders on each other; different interpretations.

Secondly, constraints result from misaligned understanding - for example purpose not clear; misalignment of requirements; prioritisation not clear.

Thirdly, there are many words implicitly associated with understanding that are not always recognised as "understanding" - for example, examining the total results of those sampled in Table 1 only $45 \%$ were deemed to be affected by understanding, yet the words 
ambiguous, unclear, assumptions etc. are used in the description of the "Scope" constraint (LOI \#1a) and unnecessary purchase requisitions to the "Sign-off Process" (LOI \#1b). These two constraints were perceived to have the biggest LOI (level of impact) on Organisation X project delivery but not implicitly recognised as relating to the flow of "Understanding."

Finally, and perhaps most damagingly, constraints result from understanding based on assumptions - for example commitments made on behalf of others; incorrect information used; dates moved without consultation; plans made by 3rd parties without consultation.

Having codified and revealed the main constraints to the general company operations through interviews and workshops, the related constraints to project delivery at Organisation X specific to the 8 Flows of lean construction were identified. A conceptual model of how the flows interacted with the delivery process is illustrated in Figure 2 . The

$8^{\text {th }}$ Flow: Shared Understanding - solid purple block - is shown at the heart of the seven flows identified by Bertelsen et al (2007). The tip of the arrow at each of issues relates to where the shared understanding must be pulled from - i.e. shared understanding must be pulled from each of the other 7 Flows. The 7 Flows are shown in a separate solid coloured block with purple outline with their related constraining issues arranged as a network. Shared understanding must be then also be pulled from each of the elements within the network of each of the 7 Hard Flows.

The model provides examples that show that a shared understanding not only underpins the knowledge and consenquent action associated with each of the 7 Hard Flows but that it permeates the project processes in this study.

\section{DISCUSSION AND CONCLUSIONS}

The title of this paper refers to machine code. This phrase is used to provide a context for the importance of understanding by equating the impact of poor understanding to that of poor machine coding. Information technologies such as Computer Aided Manufacturing use machine code to direct machines. These codes require significant attention and design to ensure the machine output is the desired one and the effort to ensure interoperability between machine codes becomes increasingly complex as the number of machines to be co-ordinated increases. This requires a need for the sharing and integration of machine codes to be explicitly considered if interfaces are to be successful. We tried to illustrate through the this paper how understanding acts like a machine code by collecting examples of where the absence of a an appropriate level of understanding constraints work flow in a project organisation.

Figure 2: Conceptual model of flow and understanding 


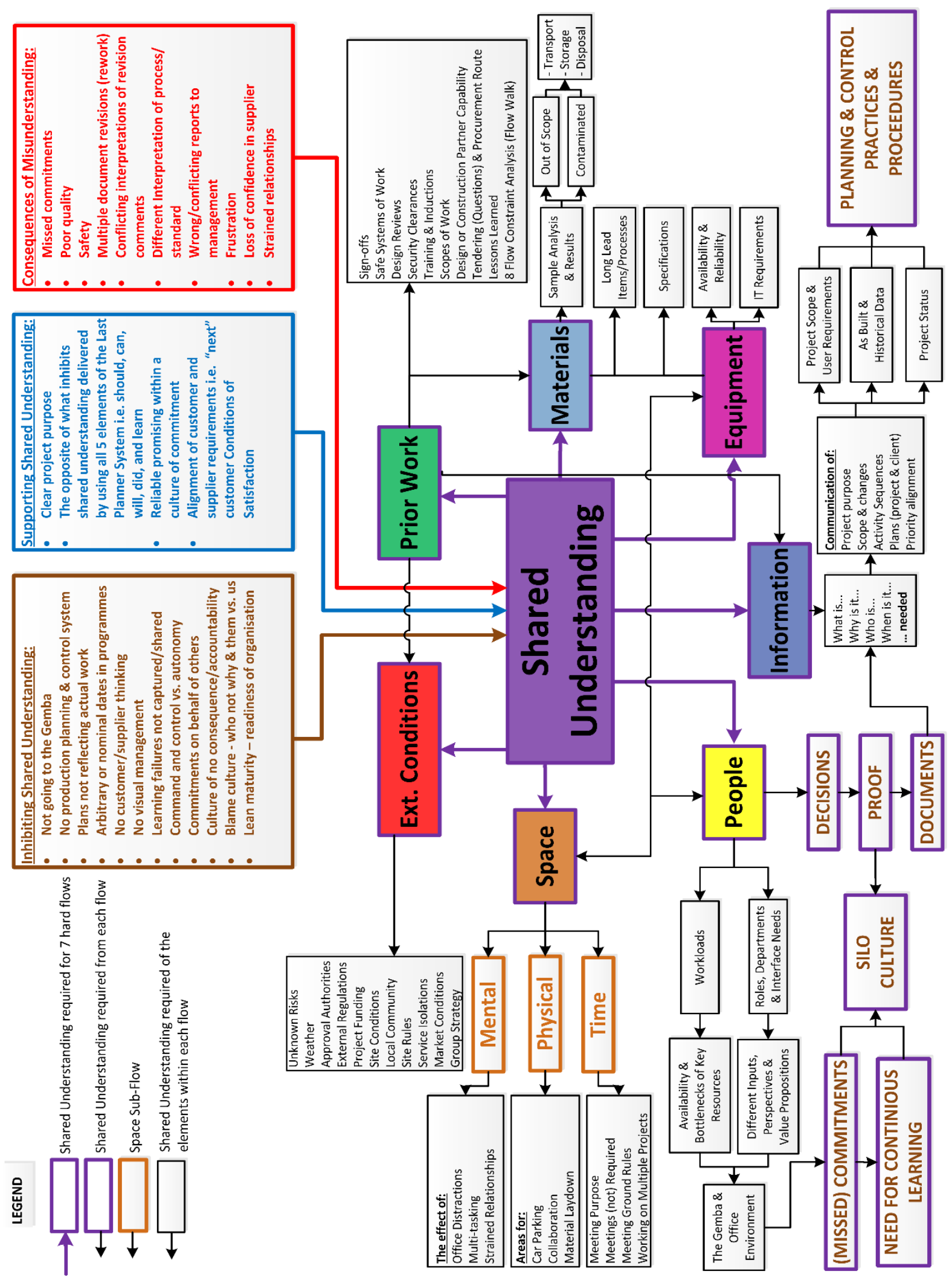

Furthermore, as with machines, if the desired outcome requires the input and collaboration of more than two people then that understanding needs to be shared and to embrace and 
engage the distributed knowledge in a way that optimises those outcomes. As the findings listed here show, even in a small and simple context there are many opportunities for this to fail. Whilst the attempt to match flow with specific constraints within a single case study does not provide a generalised solution, we believe it does provide some evidence of the disruption caused by inappropriate understanding and that these inappropriate understandings include misalignment, personal (non-shared or siloed), implicit recognition of words related to understanding, and assumption. It seems that people within a traditional organisation like the case study company, are not aware that inappropriate understanding causes many of the problems they face. It also seems that once people become aware of lean practices they also become aware of the need to create a shared understanding because they try to identify root causes of difficulty and disruption. These lean practices seem to provide a system which actively and continually removes barriers and problems through a structured approach to work and learning. The shape and nature of the shared understanding not only needs to be created for each project but must be nurtured and refreshed along the project timeline especially as things change frequently and team members come and go, sometimes unexpectedly, for example as a result of illness and temporary cover. For this latter reason it equates to a flow or moving phenomenon.

We conclude that the social and technical parts of the lean construction system must operate together. We propose however, that a shared understanding is not the entirety of the social part of the system. Leadership and motivation are also significant but that these need to be engaged to foster and preserve shared understanding.

\section{REFERENCES}

Andersen, L., (2016). "Design and Engineering - Material Order" Proc. 24rd Ann. Conf. of the Int'l. Group for Lean Construction, 21-23 July, Boston, MA, sect.1 pp. 83-92,

Bertelsen. S, Henreich. G, Koskela. L, and Rooke, J. (2007) Construction Physics. Proc 15th Ann Conf. of the Int'l. Group for Lean Construction,, July 2007, Michigan, USA pp 1326

Liker, J. K. (2004). The Toyota Way: 14 management principles from the world's greatest manufacturer. New York: McGraw Hill

Pasquire, C.L. (2012), The 8th Flow - A Common Understanding; Proc 20th Ann Conf. Of the Int'l Group for Lean Construction, July 2012, San Diego, USA

Pasquire C.L. \& Court, P.F (2013) An Exploration of Knowledge and Understanding - the Eighth Flow. Proc 21st Ann Conf. Of the Int'l Group for Lean Construction, July 2013, Forteleza, Brazil

Ryle, G. (1963). The Concept of Mind, Penguin, Harmondsworth.

Seymour. D. (1996). Developing Theory in Lean Construction. Proc 4th Ann Conf. of the Int'l. Group for Lean Construction, Birmingham, UK pp 1- 25. 